\section{RMD Open}

Rheumatic \&

Musculoskeletal Diseases

\title{
Measuring ACPA in the general population or primary care: is it useful?
}

Axel Finckh (1), Delphine Courvoisier, Celine Lamacchia, Recherche clinique en rhumatismes inflammatoires

To cite: Finckh A, Courvoisier D, Lamacchia C. Measuring ACPA in the general population or primary care: is it useful?. RMD Open 2020;6:e001085. doi:10.1136/ rmdopen-2019-001085

Received 2 November 2019 Revised 30 January 2020 Accepted 31 January 2020

\section{Check for updates}

(c) Author(s) (or their employer(s)) 2020. Re-use permitted under CC BY-NC. No commercial re-use. See rights and permissions. Published by BMJ.

Division of Rheumatology, University Hospital of Geneva, Geneva, Switzerland

Correspondence to Professor Axel Finckh; axel.finckh@hcuge.ch

\section{ABSTRACT}

Rheumatoid arthritis (RA) is associated with a significant disease burden and high costs for society. Because the disease has identifiable preclinical stages, screening and prevention have become a possibility in RA.

Anticitrullinated peptide antibodies (ACPAs) are arguably the most likely candidate biomarker to screen for RA. This paper reviews the evidence for the use of ACPAs as a screening test in the broader general population, to identify individuals at high risk of subsequent onset of RA. We will review the diagnostic properties of the test and its positive and negative predictive value in different settings. We will discuss how ACPA testing could effectively be integrated in a broader screening strategy for RA.

\section{BACKGROUND}

Screening for a disease is intimately linked to the concept of prevention. Some have even argued that screening for a disease might be unethical if patients cannot be offered preventive treatment. ${ }^{12}$ Once viewed as an unavoidably damaging disease, rheumatoid arthritis (RA) has recently become a potentially curable disease. Based on data from animal models and limited clinical evidence in RA, the existence of a critical period is proposed, a 'therapeutic window of opportunity', during which antirheumatic therapy may be capable of modifying the disease permanently or preventing it altogether. ${ }^{3-7}$ Several trials are currently exploring the impact of early, aggressive use of disease-modifying antirheumatic drugs (DMARDs) in preclinical RA. DMARDs such as abatacept, rituximab, methotrexate, methylprednisolone or hydroxychloroquine have/are being tested in individuals who do not have yet developed classifiable RA. ${ }^{8-17}$ Most preventive trials in RA have focused on secondary prevention in patients with recent onset, undifferentiated arthritis. Only few studies have explored the impact of early DMARD therapy in subjects with arthralgias, prior to clinical arthritis, or even subjects with only biomarkers for RA,

\section{Key messages}

What is already known about this subject?

- Autoantibodies associated with rheumatoid arthritis (RA), including anticitrullinated peptide antibodies (ACPAs), precede the onset of RA by several years.

- Only if preventive intervention demonstrate efficacy in reducing the incidence of subsequent onset of RA, is screening for RA warranted.

- Although cumulative evidence suggest a direct involvement of ACPA in the pathogenesis of RA itself, more extensive and rigorous experiments are needed.

How might this impact on clinical practice?

- While the diagnostic properties of ACPAs are good, the test still has low positive predictive value when applied to the general population or when the prevalence of the disease is low.

the so-called 'autoimmunity associated with RA' phase. $^{18}$

WHO has established guidelines for screening and preventive interventions. ${ }^{19}$ If RA screening and prevention is to gain acceptance, it will have to meet specific criteria established by public health agencies. ${ }^{7}$ At present, only one musculoskeletal disease meets these requirements. In osteoporosis, screening of individuals at high risk and treating patients with low bone density have demonstrated benefits. WHO general guidelines recommend among others pursuing screening only for diseases that represent a significant disease burden for society, and diseases that have an identifiable preclinical stage. ${ }^{19}$ Another prerequisite is the ability to predict an individual's risk of disease adequately and access to an effective treatment to prevent the development of the condition. ${ }^{19}$ RA certainly qualifies for a number of these conditions. Markers of early phases of RA exist and can be used before the clinical onset of disease. Studies in healthy blood donors have shown that the presence of autoantibodies, such as anticitrulinated peptide antibodies (ACPAs), 
precedes the onset of RA by several years. ${ }^{20-23}$ Almost all completed or ongoing preventive trials have used the presence of ACPA as one of their inclusion criteria. One could argue that widespread autoantibody screening makes little sense before a preventive intervention has demonstrated its ability to reduce the incidence of RA. However, even before any pharmacological intervention demonstrates efficacy in preventing RA development, one can claim that there is currently already enough evidence to recommend specific lifestyle modifications in individuals at high risk for the disease. ${ }^{24}$ The question we will be exploring in this review is whether ACPA could be used as a screening test in a broader general population or primary care setting to identify individuals who could benefit from a preventive intervention.

\section{A brief history of ACPAs}

The history of ACPA started in 1964 when Nienhuis $e t$ al reported antiperinuclear factor (APF), an antibody against human keratohyalin granules of buccal mucosa cells in the serum of patients with RA. ${ }^{25}$ Fifteen years later, antikeratin antibodies (AKA) were identified by Young et al, displaying a high specificity for RA. ${ }^{26}$ Both APF and AKA were then found to belong to a family of autoantibodies directed against citrullinated filaggrin peptides. ${ }^{27-29}$ Over the years, other citrullinated peptides were identified, such as vimentin, fibrin, fibrinogen and $\alpha$-enolase. ${ }^{30-32}$ In 2013, van Beers et al used the term 'citrullinome' to refer to the various citrullinated proteins $(\mathrm{n}=53$ in all) identified in the sera and the synovial fluid of patients with RA. ${ }^{33}$ Citrulline is a nonstandard amino acid generated by the post-translational modification of arginine by peptidylarginine deiminase enzymes, in a calcium-dependant process called citrullination. ${ }^{34}$ It occurs naturally in cell differentiation, inflammatory responses, cell apoptosis, keratinisation, gene regulation and ageing process. The citrullination causes loss basic charges, which can influence the protein structure and promote the generation of neoantigens and in turn an autoimmune response. ${ }^{34}$ Abnormal citrullination of various peptides is observed in RA, but also in other human diseases, including Alzheimer's disease, psoriasis, systemic lupus erythematosus, primary biliary cirrhosis and multiple sclerosis. ${ }^{35}{ }^{36}$ However, the development of systemic ACPAs seems to be highly specific for RA, while the significance of ACAPs in other conditions is still unclear. ${ }^{37}$

The first available ACPA test (first generation or anti-CCP1), based on the ELISA method, was developed by Eurodiagnostica in 2000 using a cyclic citrullinated peptide (CCP) derived from human filaggrin. ${ }^{38}$ Synthetic peptide libraries were then screened to select better epitopes, to improve diagnostic accuracy. ${ }^{39}$ In 2002, a second generation cyclic citrullinated peptide (CCP2) assay was introduced by Eurodiagnostica and has been widely used as routine test for ACPAs in RA. Multiple versions of anti-CCP2 kits are available from various manufacturers (Eurodiagnostica, Inova diagnostics,
Axis-Shield, Euroimmun, Phadia, etc.), with slightly different features and diagnostic accuracy for RA. ${ }^{40}$ CCP3 (third generation CCP) assays were later developed and based on additional epitopes, not present in the CCP2 antigen sequence. ${ }^{41}$ Despite some controversy in the literature, there is no clear evidence for superiority of the CCP3 compared with the CCP2 assay. However, it seems that CCP2 may be more specific in established patients with RA, whereas CCP3 may have a higher predictive value for RA development in subjects with undifferentiated inflammatory arthritis. ${ }^{42}$ Several alternative methods for detecting ACPA have been developed, including assays based on citrullinated proteins instead of peptides, such as mutated citrullinated vimentin (Orgentec), filaggrin (CPA; Genesis) or a viral citrullinated peptide, but none is widely used in routine diagnosis of RA. Bead-based chemiluminescent immunoassays have been recently developed to quantify ACPAs and may potentially improve the sensitivity due to the larger surface binding area of the bead-based assay. ${ }^{43}$

\section{The potential biological functions of ACPAs}

Even though citrullination is a common biological phenomenon, and the secretion of IgA-ACPAs occurs physiologically at mucosal sites, the development of a systemic antibody response against citrullinated peptides is fairly specific for RA. The reasons for the specificity of systemic ACPAs in RA are not completely understood, but suggest a potential role of these autoantibodies in the pathophysiological processes leading to the development of RA, but it is also possible that ACPAs just represent a bystander phenomenon.

The generation of ACPA starts in early developmental phases of RA and ACPAs are strongly predictive for the progression to established RA. Some evidence suggest that genetic (eg, the shared epitope) and environmental risk factors (eg, tobacco smoke) act in concert to increase the formation of citrullinated proteins, to promote their presentation to the immune system, to break the tolerance towards these antigens and lead to the development of ACPA. ${ }^{44}$ Interestingly, these autoantibodies are transformed over the period of time, from their systemic appearance up to RA onset, with both qualitative and quantitative changes, extensive diversification, increased avidity, new isotypes and acquisition of specific agalactosylation and core fucosylation profiles. ${ }^{45}$ Several investigations have suggested mechanisms by which ACPA may be directly pathogenic in RA. ${ }^{46}$ One potential mechanism relates to the ability of ACPA to form immune complexes (IC) that can activate inflammatory cells. The effector functions of ACPA containing IC can be enhanced by the concomitant presence of rheumatoid factor (RF), suggesting a potential synergetic role of ACPA and RF, clinically linked to a more severe arthritis. ${ }^{47-49}$ Another mechanism by which ACPA may interfere in RA pathogenesis could be via the stimulation of neutrophil extracellular traps formation, a phenomenon that externalises citrullinated autoantigens and 
immunostimulatory molecules, leading to a perpetuation of inflammation and autoimmunisation processes in RA. ${ }^{50}$ Another mechanism proposed for ACPAs suggests that these antibodies function as agonists for a receptormediated cell response and directly induce both pain and osteoclastogenesis. ${ }^{5152}$ However, more data are needed to support the finding of direct binding of ACPAs to molecules expressed on the surface of osteoclasts. ${ }^{53}$

While several authors have proposed a direct pathogenic role of ACPAs, it is also possible that these autoantibodies just reflect pathogenic cellular and humoral activity leading to the development of RA, but without affecting directly joint inflammation. In other terms, ACPA could be innocent bystanders, generated by the biological processes characteristic of the disease. Toes and Pisetsky have recently drafted several recommendations to define with more experimental rigour the potential pathogenic activity of either polyclonal or monoclonal antibodies. ${ }^{53}$ Although ACPAs are highly cross reactive and bind a large variety of citrullinated proteins, their primary antigenic target relevant to RA and its precise tissue site are unknown.

\section{Screening, case finding and diagnosis}

Conceptually, screening needs to be distinguished from case finding and from diagnosis. The principal aim of screening is to detect potential early signs of disease in a large, generally asymptomatic, population. The principal aim of case finding is to search systematically for undiagnosed early disease in groups at increased risk for the disease. ${ }^{54}$ The principal aim of diagnosis is to establish the presence or absence of disease in symptomatic individuals. The characteristic of tests will need to be tailored for its primary use. A screening test needs to be inexpensive and easy to perform to be acceptable to a healthy population, and will generally favour sensitivity over specificity in order not to miss potential cases. ${ }^{19} \mathrm{On}$ the contrary, a diagnostic test may be more invasive and more expensive in order to establish disease, and tends to favour specificity over sensitivity.

\section{ACPAs as a diagnostic test}

What makes a good diagnostic test? First, the biomarker should have good sensitivity, which means correctly being positive (above the threshold) in patients with the disease. Second, the biomarker should also have good specificity, meaning correctly being negative (below the threshold) in people without the disease. Furthermore, the test needs to provide good positive and negative predictive values (PPV and NPV). PPV estimates the probability for a person having a positive test, to really have the disease, while NPV estimates the probability for a person having a negative test, to actually not have the disease. However, even tests with very good sensitivity and specificity may not provide good predictive values, because the predictive value depends on the sensitivity and the specificity of a diagnostic test, and on the probability of the disease in the population. The mathematical link among sensitivity, specificity, prevalence and predictive values, often called Bayes' theorem, is not always well-understood by physicians. ${ }^{55}$ Indeed, more than $80 \%$ of physicians did not correctly take into account the prevalence when asked to estimate the predictive ability of a given test.

Two scenarios may illustrate the differential value of ACPA testing in diagnosing RA in patients with recentonset undifferentiated arthritis ${ }^{56}:$ (1) A young male with a 2-month history of arthritis of both knees, some morning stiffness, no RF and slightly raised $\mathrm{C}$ reactive protein $(<50 \mathrm{mg} / \mathrm{L})$ has little risk for RA within the next year (estimated probability between $0 \%$ and $6 \%) .{ }^{57}$ Even if this patient had a positive ACPA test, it would not increase substantially his risk of developing RA (estimated post-test probability, $\sim 7 \%) .{ }^{57}$ (2) On the other side of the spectrum, a mid-aged woman with a 2-month history of painful and swollen metacarpophalangeal joints of a single hand, some morning stiffness, no RF and slightly raised $\mathrm{C}$ reactive protein level $(<50 \mathrm{mg} / \mathrm{L})$ has a risk of developing RA within the next year of approximately $26 \%{ }^{57}$ If this patient had a positive-ACPA test, her risk of having RA would climb to $67 \% .^{57}$ These scenarios illustrate a major consequence of Bayes' theorem: the value of a positive ACPA test depends decisively on the a priori likelihood of RA. ${ }^{56}$

While ACPAs have a higher specificity than the $\mathrm{RF}^{58}$ the sensitivity and specificity of ACPAs for RA remain far from perfect. ${ }^{59} \mathrm{~A}$ meta-analysis of the diagnostic performance of ACPAs in established RA combined 37 studies and found a pooled sensitivity of $67 \%(95 \%$ CI $65 \%$ to $68 \%)$ and a pooled specificity of $95 \%(95 \%$ CI $95 \%$ to $96 \%){ }^{58}$ The limited sensitivity of the test can be explained by the fact that not all patients with RA seem to have autoantibodies ('seronegative disease'), even if in some of the patients with ACPA-negative RA have other autoantibodies. The limited specificity of ACPAs can be explained by the fact that these antibodies also occur in other conditions, such as periodontal disease ${ }^{6061}$ chronic lung diseases ${ }^{62}$ or other autoimmune diseases. ${ }^{63}$

\section{ACPAs as a screening test}

ACPAs are present in $0.8 \%$ of Caucasians without $\mathrm{RA}^{64}$ and in $1.7 \%$ of Asians without known autoimmune disease.$^{65}$ Several factors are known to be associated with the presence of ACPA, such as older age, in particular for women where the perimenopausal period seems to be associated with an increased prevalence, ${ }^{66}$ tobacco smoking and undifferentiated joint complaints.

The predictive value of ACPA testing will differ when applied as a screening tool in an asymptomatic general patient population from when it is applied as a diagnostic tool, because the pretest probability of RA will be much lower (figure 1). Let us illustrate this with a real-world example: screening for ACPA positivity was performed in large population representative cohort from Sweden of over 12000 individuals. ${ }^{59}$ After excluding patients already known to have established RA, 247 participants tested ACPA positive (2\%). Of these, 21 developed incident RA 


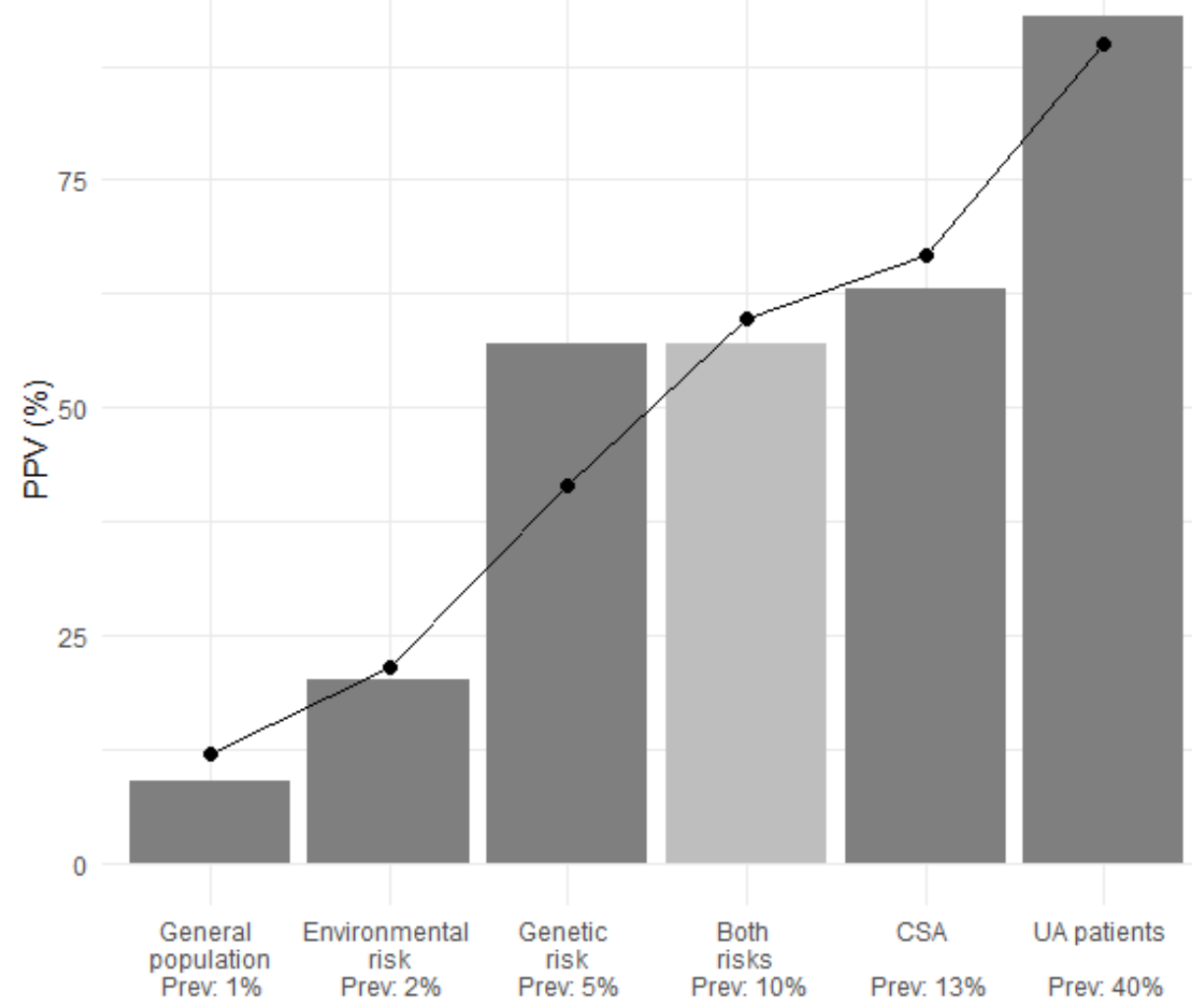

Figure 1 Positive predictive value (PPV) of anticitrulinated peptide antibody (ACPA) testing in different at risk populations: hypothetical and reported predictive ability by incidence rates of rheumatoid arthritis (RA). The PPV of ACPAs testing increases in populations at higher a priori risk for the disease. The line displays the hypothetical PPV based on the established diagnostic properties of ACPA, with a specificity of $67 \%$ and a sensitivity of $95 \%{ }^{58}$ The barchart displays actual PPV reported in various at risk populations with different incidence rates of RA. ${ }^{5968992}$ CSA, clinically suspect arthralgia patients; UA, undifferentiated arthritis.

within the next 3 years, which results in a PPV of less than $9 \%{ }^{59}$ While it can be argued that a follow-up period of 3 years might be insufficient, the results remain clearly disappointing and do not support using ACPA indiscriminately in the general population.

While using ACPA as a screening tool in the general population does not make much sense because of insufficient PPV, it could add up in a population at higher baseline risk of developing RA. Several of such at risk groups have been identified. For example, in individuals genetically at increased risk for RA, such as family members of patients who have an autoimmune disease or individuals of an ethnic group known to have a high prevalence of RA. Thus, the PPV for RA at 5 years for a positive ACPA test was $58 \%$ in first degree relatives of patients with RA, ${ }^{67}$ and the PPV for RA at 5 years was $56 \%$ in a particular indigenous American Indian tribe. ${ }^{68}$ While the PPV for RA in these individuals at risk for RA may vary substantially depending on the strength of the genetic risk or the prevalence of other conditions known to promote the production of ACPAs, ${ }^{60-63}$ the PPV of ACPAs is overall substantially better when screening populations at higher a priori risk for the disease (figure 1). Other at risk populations warranting screening could be groups exposed to specific environmental risk factors of RA or having specific comorbidities that put them at higher risk. Examples of environmental risk factors increasing the likelihood of RA are, for example, obesity, tobacco smoking or other inhaled pollutants, certain nutritional habits; viral infections have also been suggested to increase the odds of developing the disease. ${ }^{69-72}$ Hormonal factors such as the rapid decline in ovarian function at menopause or after a total hysterectomy have been proposed as a condition warranting screening for autoimmunity. ${ }^{66}$ Other autoimmune comorbidities, such as autoimmune thyroiditis, have been demonstrated to increase the risk of RA and may justify regular screening for RA. ${ }^{73}$ Chronic periodontitis, chronic interstitial lung disease or chronic diarrhoea have also been proposed as comorbid conditions increasing the risk for future RA. ${ }^{60-62} 7475$ In order to integrate the different risk factors, clinical prediction rules have been developed to estimate the risk of progression to RA. ${ }^{76}$ Some prediction rules are solely on easily ascertained lifestyle factors $^{77}$; others have combined family history, genetic markers, serological markers and environmental factors, with a good discriminative ability ${ }^{78-81}$ Validated 
prediction rules may be useful to select at-risk populations with a higher likelihood of developing RA prior to ACPA screening.

Another approach to increase the predictive value of ACPAs could be to enhance the diagnostic performances of the test to better suit the needs of screening. Some have modified the cut-off level and used higher titters of ACPAs, or have required multiple ACPA reactivity's (called 'fine-specificity ACPAs') ${ }^{59}$ Other have proposed to combine ACPAs with additional biomarkers to increase its specificity or its sensitivity, for example, when both RF and ACPA are present, the specificity for future RA appears to be close to $100 \%{ }^{23}$ The discriminative power of ACPAs may be improved by combining other putative biomarkers, such as genetic markers, ${ }^{82}$ highly sensitive $\mathrm{C}$ reactive protein, ${ }^{83}$ cytokine and chemokine profiles, ${ }^{84}$ and other autoantibodies, ${ }^{2285}$ in combination or in series. ${ }^{5686}$ Still others have proposed to add imaging modalities, such as MRI or articular ultrasound. ${ }^{8788}$ but the optimal combination of biomarkers and imaging tests to predict future development of RA has not yet been established.

WHO also recommends to consider the cost effectiveness of screening, to weigh the costs involved in identifying a case against the global medical expenditure in a particular setting. ${ }^{19}$ Unfortunately, combining several biomarkers or imaging modalities is likely to decrease the cost effectiveness of screening for RA and should probably be reserved for diagnosis rather than for screening strategies. Liang et al have proposed that screening and case finding may be realistically and cost effectively accomplished in a fairly infrequent condition, such as RA, by a serial testing strategy. ${ }^{54} \mathrm{He}$ proposed to start screening with an inexpensive, sensitive test to prescreen individuals, which could involve an internet questionnaire or a prediction rule. ${ }^{54}$ Individual's testing positive would be proposed increasingly more specific tests, which includes ACPAs, and ultimately, a medical assessment for diagnosis and confirmation.

\section{CONCLUSIONS}

Given the low prevalence of RA or of preclinical phases of RA in the general population, in this setting ACPAs are probably not an adequate screening tool in isolation. In an unselected general population and as a first-line screening tool, ACPAs have insufficient PPV, result in a high number of false-positive tests and generate unjustifiable medical costs. As the rheumatological community is starting to discuss the risks of overdiagnosis and overtreatment, ${ }^{89} 90$ other means for the initial screening of RA should be considered. Taking advantage of the well-established risk factors of the disease, using validated prediction rules or internet-based techniques could be an attractive option to preselect a population with a higher pretest probability of RA, warranting ACPA testing. ${ }^{54}$ ACPA testing is an effective diagnostic tool and useful for RA case finding in selected at risk populations.
Collaborators Recherche clinique en rhumatismes inflammatoires: 0 . Studer, E. Trunk, B. Gilbert.

Contributors All authors have seen and approved the final manuscript and contributed significantly to this work (meet criteria for authorship).

Funding Study was funded by Fondation Jean et Linette Warnery.

Competing interests The author's institution has a scientific collaboration with Inova and Thermofisher, 2 producers of ACPA tests. The research collaboration is scientific and does not involve any monetary compensation or other kind of benefits.

Patient consent for publication Not required.

Provenance and peer review Commissioned; externally peer reviewed.

Data availability statement No additional data are available.

Open access This is an open access article distributed in accordance with the Creative Commons Attribution Non Commercial (CC BY-NC 4.0) license, which permits others to distribute, remix, adapt, build upon this work non-commercially, and license their derivative works on different terms, provided the original work is properly cited, appropriate credit is given, any changes made indicated, and the use is non-commercial. See: http://creativecommons.org/licenses/by-nc/4.0/.

ORCID iD

Axel Finckh http://orcid.org/0000-0002-1210-4347

\section{REFERENCES}

1 Notkins AL. New predictors of disease. Sci Am 2007;296:72-9.

2 Organisation WH. Preventing chronic disease: a vital investment. WHO Press, 2005.

3 Finckh A, Escher M, Liang MH, et al. Preventive treatments for rheumatoid arthritis: issues regarding patient preferences. Curr Rheumatol Rep 2016;18:51.

4 Klareskog L, Gregersen PK, Huizinga TWJ. Prevention of autoimmune rheumatic disease: state of the art and future perspectives. Ann Rheum Dis 2010;69:2062-6.

5 Bykerk VP, Hazes JM. When does rheumatoid arthritis start and can it be stopped before it does? Ann Rheum Dis 2010;69:473-5.

6 Deane KD. Can rheumatoid arthritis be prevented? Best Pract Res Clin Rheumatol 2013;27:467-85.

7 Finckh A, Deane KD. Prevention of rheumatic diseases: strategies, caveats, and future directions. Rheum Dis Clin North Am 2014;40:771-85.

8 Al-Laith M, Cope AP. Arthritis prevention in the pre-clinical phase of rheumatoid arthritis with abatacept (APIPPRA). ISRCTN registry 2014.

9 van Schaardenburg D. Statins to prevent rheumatoid arthritis (STAPRA), 2015. Available: http://www.trialregister.nl/trialreg/admin/ rctview.asp?TC=5265 [Accessed 19 Dec 2017].

10 van Dongen $\mathrm{H}$, van Aken J, Lard LR, et al. Efficacy of methotrexate treatment in patients with probable rheumatoid arthritis: a doubleblind, randomized, placebo-controlled trial. Arthritis Rheum 2007;56:1424-32.

11 Machold KP, Landewé R, Smolen JS, et al. The stop arthritis very early (save) trial, an international multicentre, randomised, doubleblind, placebo-controlled trial on glucocorticoids in very early arthritis. Ann Rheum Dis 2010;69:495-502.

12 Emery P, Durez P, Dougados M, et al. Impact of T-cell costimulation modulation in patients with undifferentiated inflammatory arthritis or very early rheumatoid arthritis: a clinical and imaging study of abatacept (the adjust trial). Ann Rheum Dis 2010;69:510-6.

13 Bos WH, Dijkmans BAC, Boers M, et al. Effect of dexamethasone on autoantibody levels and arthritis development in patients with arthralgia: a randomised trial. Ann Rheum Dis 2010;69:571-4.

14 Tak P. Prevention of clinically manifest rheumatoid arthritis by B cell directed therapy in the earliest phase of the disease. Nederland trial register 2012 23.08.2010. Available: http://www.trialregister.nl/ trialreg/admin/rctview.asp?TC=2442 [Accessed $18 \mathrm{Jul}$ 2012].

15 Neff T. Rheumatoid arthritis prevention study getting ready to roll. UCHealth insider. Denver: University of Colorado, 2015: 1-2.

16 Gerlag DM, Safy M, Maijer KI, et al. Effects of B-cell directed therapy on the preclinical stage of rheumatoid arthritis: the PRAIRI study. Ann Rheum Dis 2019;78:179-85.

17 Einarsson JT, Evert M, Geborek P, et al. Rituximab in clinical practice: dosage, drug adherence, Ig levels, infections, and drug antibodies. Clin Rheumatol 2017;36:2743-50.

18 Gerlag DM, Raza K, van Baarsen LGM, et al. EULAR recommendations for terminology and research in individuals at risk 
of rheumatoid arthritis: report from the study Group for risk factors for rheumatoid arthritis. Ann Rheum Dis 2012;71:638-41.

19 Wilson JM, Jungner YG. [Principles and practice of mass screening for disease]. Bol Oficina Sanit Panam 1968;65:281-393.

20 Jorgensen KT, Wiik A, Pedersen M, et al. Cytokines, autoantibodies and viral antibodies in premorbid and postdiagnostic sera from patients with rheumatoid arthritis: case-control study nested in a cohort of Norwegian blood donors. Ann Rheum Dis 2008;67:860-6.

21 Karlson EW, Chibnik LB, Tworoger SS, et al. Biomarkers of inflammation and development of rheumatoid arthritis in women from two prospective cohort studies. Arthritis Rheum 2009;60:641-52.

22 Nielen MMJ, van Schaardenburg D, Reesink HW, et al. Specific autoantibodies precede the symptoms of rheumatoid arthritis: a study of serial measurements in blood donors. Arthritis Rheum 2004;50:380-6.

23 Rantapää-Dahlqvist S, de Jong BAW, Berglin E, et al. Antibodies against cyclic citrullinated peptide and IgA rheumatoid factor predict the development of rheumatoid arthritis. Arthritis Rheum 2003:48:2741-9.

24 Liu X, Tedeschi SK, Barbhaiya M, et al. Impact and Timing of Smoking Cessation on Reducing Risk of Rheumatoid Arthritis Among Women in the Nurses' Health Studies. Arthritis Care Res 2019;71:914-24.

25 Nienhuis RLF, Mandema E, Smids C. New serum factor in patients with rheumatoid arthritis: the antiperinuclear factor. Ann Rheum Dis 1964;23:302-5.

26 Young BJ, Mallya RK, Leslie RD, et al. Anti-keratin antibodies in rheumatoid arthritis. BMJ 1979;2:97-9.

27 Sebbag M, Simon M, Vincent C, et al. The antiperinuclear factor and the so-called antikeratin antibodies are the same rheumatoid arthritis-specific autoantibodies. J Clin Invest 1995;95:2672-9.

28 Schellekens GA, de Jong BA, van den Hoogen FH, et al. Citrulline is an essential constituent of antigenic determinants recognized by rheumatoid arthritis-specific autoantibodies. J Clin Invest 1998;101:273-81.

29 Girbal-Neuhauser E, Durieux JJ, Arnaud M, et al. The epitopes targeted by the rheumatoid arthritis-associated antifilaggrin autoantibodies are posttranslationally generated on various sites of (pro)filaggrin by deimination of arginine residues. $J$ Immunol 1999:162:585-94

30 Sebbag M, Moinard N, Auger I, et al. Epitopes of human fibrin recognized by the rheumatoid arthritis-specific autoantibodies to citrullinated proteins. Eur J Immunol 2006;36:2250-63.

31 Vossenaar ER, Després N, Lapointe E, et al. Rheumatoid arthritis specific anti-Sa antibodies target citrullinated vimentin. Arthritis Res Ther 2004;6:R142-50

32 Takizawa Yet al. Citrullinated fibrinogen detected as a soluble citrullinated autoantigen in rheumatoid arthritis synovial fluids. Ann Rheum Dis 2006;65:1013-20.

33 van Beers JJBC, Schwarte CM, Stammen-Vogelzangs J, et al. The rheumatoid arthritis synovial fluid citrullinome reveals novel citrullinated epitopes in apolipoprotein $\mathrm{E}$, myeloid nuclear differentiation antigen, and $\beta$-actin. Arthritis Rheum 2013;65:69-80.

34 Valesini G, Gerardi MC, lannuccelli C, et al. Citrullination and autoimmunity. Autoimmun Rev 2015;14:490-7.

35 György B, Tóth E, Tarcsa E, et al. Citrullination: a posttranslational modification in health and disease. Int J Biochem Cell Biol 2006;38:1662-77.

36 Baka Z, György B, Géher P, et al. Citrullination under physiological and pathological conditions. Joint Bone Spine 2012;79:431-6.

37 Payet J, Goulvestre C, Bialé L, et al. Anticyclic citrullinated peptide antibodies in rheumatoid and nonrheumatoid rheumatic disorders: experience with 1162 patients. J Rheumatol 2014;41:2395-402.

38 Schellekens GA, Visser $\mathrm{H}$, de Jong BA, et al. The diagnostic properties of rheumatoid arthritis antibodies recognizing a cyclic citrullinated peptide. Arthritis Rheum 2000;43:155-63.

39 van Gaalen FA, Visser H, Huizinga TW. A comparison of the diagnostic accuracy and prognostic value of the first and second anti-cyclic citrullinated peptides (CCP1 and CCP2) autoantibody tests for rheumatoid arthritis. Ann Rheum Dis 2005;64:1510-2.

40 Aggarwal R, Liao K, Nair R, et al. Anti-citrullinated peptide antibody assays and their role in the diagnosis of rheumatoid arthritis. Arthritis Care Res 2009;61:1472-83.

41 Saraux A, Berthelot JM, Devauchelle V, et al. Value of antibodies to citrulline-containing peptides for diagnosing early rheumatoid arthritis. J Rheumatol 2003;30:2535-9.

42 Demoruelle MK, Parish MC, Derber LA, et al. Performance of anticyclic citrullinated peptide assays differs in subjects at increased risk of rheumatoid arthritis and subjects with established disease. Arthritis Rheum 2013;65:2243-52.
43 Mahler M, Bentow C, Serra J, et al. Detection of autoantibodies using chemiluminescence technologies. Immunopharmacol Immunotoxicol 2016;38:14-20.

44 Klareskog L, Stolt $\mathrm{P}$, Lundberg $\mathrm{K}$, et al. A new model for an etiology of rheumatoid arthritis: Smoking may trigger HLA-DR (shared epitope)-restricted immune reactions to autoantigens modified by citrullination. Arthritis Rheum 2006;54:38-46.

45 Kurowska W, Kuca-Warnawin EH, Radzikowska A, et al. The role of anti-citrullinated protein antibodies (AcpA) in the pathogenesis of rheumatoid arthritis. Cejoi 2017;42:390-8.

46 England BR, Thiele GM, Mikuls TR. Anticitrullinated protein antibodies: origin and role in the pathogenesis of rheumatoid arthritis. Curr Opin Rheumatol 2017;29:57-64.

47 Anquetil F, Clavel C, Offer G, et al. Igm and IgA rheumatoid factors purified from rheumatoid arthritis sera boost the Fc receptorand complement-dependent effector functions of the diseasespecific anti-citrullinated protein autoantibodies. J Immunol 2015;194:3664-74.

48 Laurent L, Anquetil F, Clavel C, et al. Igm rheumatoid factor amplifies the inflammatory response of macrophages induced by the rheumatoid arthritis-specific immune complexes containing anticitrullinated protein antibodies. Ann Rheum Dis 2015;74:1425-31.

49 Sokolove J, Johnson DS, Lahey LJ, et al. Rheumatoid factor as a potentiator of anti-citrullinated protein antibody-mediated inflammation in rheumatoid arthritis. Arthritis Rheumatol 2014;66:813-21.

50 Khandpur R, Carmona-Rivera C, Vivekanandan-Giri A, et al. Nets are a source of citrullinated autoantigens and stimulate inflammatory responses in rheumatoid arthritis. Sci Transl Med 2013;5:178ra140.

51 Krishnamurthy A, Joshua V, Haj Hensvold A, et al. Identification of a novel chemokine-dependent molecular mechanism underlying rheumatoid arthritis-associated autoantibody-mediated bone loss. Ann Rheum Dis 2016;75:721-9.

52 Wigerblad G, Bas DB, Fernades-Cerqueira C, et al. Autoantibodies to citrullinated proteins induce joint pain independent of inflammation via a chemokine-dependent mechanism. Ann Rheum Dis 2016;75:730-8.

53 Toes R, Pisetsky DS. Pathogenic effector functions of AcpA: where do we stand? Ann Rheum Dis 2019;78:716-21.

54 Liang $\mathrm{MH}$, Couto MCM, Duarte CCM, et al. An Internet-based technique for the identification of persons with symptoms of inflammatory polyarthritis of less than 12 weeks. Clin Rheumatol 2015;34:465-70

55 Agoritsas T, Courvoisier DS, Combescure C, et al. Does prevalence matter to physicians in estimating post-test probability of disease? A randomized trial. J Gen Intern Med 2011;26:373-8.

56 Finckh A, Liang MH. Anti-Cyclic citrullinated peptide antibodies in the diagnosis of rheumatoid arthritis: Bayes clears the haze. Ann Intern Med 2007;146:816.

57 van der Helm-vanMil AHM, le Cessie S, van Dongen $\mathrm{H}$, et al. A prediction rule for disease outcome in patients with recentonset undifferentiated arthritis: how to guide individual treatment decisions. Arthritis Rheum 2007;56:433-40.

58 Nishimura K, Sugiyama D, Kogata Y, et al. Meta-Analysis: diagnostic accuracy of anti-cyclic citrullinated peptide antibody and rheumatoid factor for rheumatoid arthritis. Ann Intern Med 2007;146:797.

59 Hensvold AH, Frisell T, Magnusson PKE, et al. How well do ACPA discriminate and predict RA in the general population: a study based on 12590 population-representative Swedish twins. Ann Rheum Dis 2017;76:119-25.

60 Loutan L, Alpizar-Rodriguez D, Courvoisier DS, et al. Periodontal status correlates with anti-citrullinated protein antibodies in firstdegree relatives of individuals with rheumatoid arthritis. $J$ Clin Periodontol 2019;46:690-8.

61 Mankia K, Cheng Z, Do T, et al. Prevalence of periodontal disease and periodontopathic bacteria in anti-cyclic citrullinated protein antibody-positive at-risk adults without arthritis. JAMA Netw Open 2019:2:e195394.

62 Sigari N, Moghimi N, Shahraki FS, et al. Anti-Cyclic citrullinated peptide (CCP) antibody in patients with wood-smoke-induced chronic obstructive pulmonary disease (COPD) without rheumatoid arthritis. Rheumatol Int 2015;35:85-91.

63 Fabien N, Olsson N-O, Goetz J, et al. Prevalence of autoantibodies to cyclic citrullinated peptide in patients with rheumatic diseases other than rheumatoid arthritis: a French multicenter study. Clin Rev Allergy Immunol 2008;34:40-4.

64 van Zanten A, Arends S, Roozendaal C, et al. Presence of anticitrullinated protein antibodies in a large population-based cohort from the Netherlands. Ann Rheum Dis 2017;76:1184-90. 
65 Terao C, Ohmura K, Ikari K, et al. Effects of smoking and shared epitope on the production of anti-citrullinated peptide antibody in a Japanese adult population. Arthritis Care Res 2014;66:1818-27.

66 Alpizar-Rodriguez D, Mueller RB, Möller B, et al. Female hormonal factors and the development of anti-citrullinated protein antibodies in women at risk of rheumatoid arthritis. Rheumatology 2017; 56:1579-85.

67 Ramos-Remus C, Castillo-Ortiz JD, Aguilar-Lozano L, et al. Autoantibodies in predicting rheumatoid arthritis in healthy relatives of rheumatoid arthritis patients. Arthritis \& rheumatology 2015.

68 Tanner S, Dufault B, Smolik I, et al. A prospective study of the development of inflammatory arthritis in the family members of Indigenous North American people with rheumatoid arthritis. Arthritis Rheumatol 2019;71:1494-503.

69 Costenbader K, Karlson E. Epstein-Barr virus and rheumatoid arthritis: is there a link? Arthritis Res Ther 2006;8:204.10.1186/ $\operatorname{ar} 1893$

70 Hart JE, Laden F, Puett RC, et al. Exposure to traffic pollution and increased risk of rheumatoid arthritis. Environ Health Perspect 2009;117:1065-9.

71 Lu B, Solomon DH, Costenbader $\mathrm{KH}$, et al. Alcohol consumption and markers of inflammation in women with preclinical rheumatoid arthritis. Arthritis \& Rheumatism 2010;62:3554-9.

72 Källberg H, Jacobsen S, Bengtsson C, et al. Alcohol consumption is associated with decreased risk of rheumatoid arthritis: results from two Scandinavian case-control studies. Ann Rheum Dis 2009;68:222-7.

73 Boelaert K, Newby PR, Simmonds MJ, et al. Prevalence and relative risk of other autoimmune diseases in subjects with autoimmune thyroid disease. Am J Med 2010;123:183.e1-183.e9.

74 Demoruelle MK, Solomon JJ, Fischer A, et al. The lung may play a role in the pathogenesis of rheumatoid arthritis. Int J Clin Rheumtol 2014;9:295-309.

75 Seror R, Gusto G, Boutron-Ruault MC, et al. Passive smoking in childhood and history of chronic diarrhea increases the risk of developing rheumatoid arthritis (rA). Annals of the Rheumatic Diseases 2017;160.

76 Turk SA, van Beers-Tas MH, van Schaardenburg D. Prediction of future rheumatoid arthritis. Rheum Dis Clin North Am 2014:40:753-70.

77 Lahiri M, Luben RN, Morgan C, et al. Using lifestyle factors to identify individuals at higher risk of inflammatory polyarthritis (results from the European prospective investigation of CancerNorfolk and the Norfolk arthritis Register-the EPIC-2-NOAR study). AnnRheumDis 2013

78 Karlson EW, Ding B, Keenan BT, et al. Association of environmental and genetic factors and gene-environment interactions with risk of developing rheumatoid arthritis. Arthritis Care Res 2013;65:1147-56.10.1002/acr.22005
79 Sparks JA, Chen CY, Jiang X, et al. Improved performance of epidemiologic and genetic risk models for rheumatoid arthritis serologic phenotypes using family history. Ann Rheum Dis 2014.

80 Scott IC, Seegobin SD, Steer S, et al. Predicting the risk of rheumatoid arthritis and its age of onset through modelling genetic risk variants with smoking. PLoS Genet 2013;9:e1003808.

81 van de Stadt LA, Witte BI, Bos WH, et al. A prediction rule for the development of arthritis in seropositive arthralgia patients. Ann Rheum Dis 2013;72:1920-6.

82 Gregersen PK. Translating risk of disease from genetic elements. Washington, DC: American College of Rheumatology Meeting; 2006, 2006.

83 Nielen MMJ, van Schaardenburg D, Reesink HW, et al. Simultaneous development of acute phase response and autoantibodies in preclinical rheumatoid arthritis. Ann Rheum Dis 2006;65:535-7.

84 Deane KD, O'Donnell Cl, Hueber W, et al. The number of elevated cytokines and chemokines in preclinical seropositive rheumatoid arthritis predicts time to diagnosis in an age-dependent manner. Arthritis Rheum 2010;62:3161-72.

85 Gan RW, Trouw LA, Shi J, et al. Anti-carbamylated protein antibodies are present prior to rheumatoid arthritis and are associated with its future diagnosis. J Rheumatol 2015;42:572-9.

86 Vander Cruyssen B, Hoffman IEA, Peene I, et al. Prediction models for rheumatoid arthritis during diagnostic investigation: evaluation of combinations of rheumatoid factor, anti-citrullinated protein/peptide antibodies and the human leucocyte antigen-shared epitope. Ann Rheum Dis 2007;66:364-9.

87 Boer AC, Wouters F, Dakkak YJ, et al. Improving the feasibility of $\mathrm{MRI}$ in clinically suspect arthralgia for prediction of rheumatoid arthritis by omitting scanning of the feet. Rheumatology 2019;72.

88 Brulhart L, Alpízar-Rodríguez D, Nissen MS, et al. Ultrasound is not associated with the presence of systemic autoimmunity or symptoms in individuals at risk for rheumatoid arthritis. RMD Open 2019;5:e000922.

89 Landewe RBM. Response to: 'Early identification of rheumatoid arthritis; the risk of overtreatment in perspective' by Landewe. Ann Rheum Dis 2018.

90 Landewe RBM. Overdiagnosis and overtreatment in rheumatology: a little caution is in order. Ann Rheum Dis 2018;77:1394-6.

91 Ten Brinck RM, van Steenbergen HW, van Delft MAM, et al. The risk of individual autoantibodies, autoantibody combinations and levels for arthritis development in clinically suspect arthralgia. Rheumatology 2017;56:2145-53.

92 van Gaalen FA, Linn-Rasker SP, van Venrooij WJ, et al. Autoantibodies to cyclic citrullinated peptides predict progression to rheumatoid arthritis in patients with undifferentiated arthritis: a prospective cohort study. Arthritis Rheum 2004;50:709-15. 